\title{
Effects of nicotine on regional blood flow in the olfactory bulb in response to olfactory nerve stimulation
}

\author{
Sae Uchida* ${ }^{*}$ and Fusako Kagitani
}

\begin{abstract}
This study examined the effect of olfactory nerve stimulation on regional cerebral blood flow and assessed the effect of intravenous nicotine administration on this response in anesthetized rats. Regional cerebral blood flow was measured with laser Doppler flowmetry or laser speckle contrast imaging. Unilateral olfactory nerve stimulation for 5 s produced current $(\geq 100 \mu \mathrm{A})$ and frequency-dependent $(\geq 5 \mathrm{~Hz}$ ) increases in blood flow in the olfactory bulb ipsilateral to the stimulus. The increased olfactory bulb blood flow peaked at $30 \pm 7 \%$ using stimulus parameters of $300 \mu \mathrm{A}$ and $20 \mathrm{~Hz}$. Nerve stimulation did not change frontal cortical blood flow or mean arterial pressure. The intravenous injection of nicotine $(30 \mu \mathrm{g} / \mathrm{kg})$ augmented the olfactory bulb blood flow response to nerve stimulation $(20 \mathrm{~Hz}$, $300 \mu \mathrm{A}$ ) by approximately 1.5 -fold (60-s area after the stimulation). These results indicate that olfactory nerve stimulation increases olfactory bulb blood flow, and the response is potentiated by the activation of nicotinic cholinergic transmission.
\end{abstract}

Keywords: Olfactory bulb, Olfactory nerve stimulation, Regional cerebral blood flow, Nicotinic acetylcholine receptor, Rat

\section{Introduction}

The cholinergic neurons originating in the basal forebrain send projections to the neocortex, hippocampus, and olfactory bulb that contribute to cognition, memory, and olfactory function, respectively [1-3]. Our research group previously found in anesthetized rats that activation of basal forebrain cholinergic neurons produces an increase in regional blood flow in the neocortex [4-7] and hippocampus [8], whereas it does not influence blood flow in the olfactory bulb [9]. Blood flow in the olfactory bulb is reportedly increased by odor stimulation in association with neuronal activities [10-14]. Our recent study confirmed that odor stimulation (5\% amyl acetate) produces an increase in blood flow in the olfactory bulb in anesthetized rats [15].

*Correspondence: suchida@tmig.or.jp

Department of Autonomic Neuroscience, Tokyo Metropolitan Institute

of Gerontology, 35-2 Sakaecho, Itabashi-ku, Tokyo 173-0015, Japan
The olfactory nerve transmits information about the sense of smell from the olfactory epithelium to the olfactory bulb. Rodent studies have reported that the olfactory nerve increases its firing frequencies depending on the odor concentration [16-18]. Therefore, we can assume that the olfactory nerve is involved in the odor stimulation-induced increase in blood flow in the olfactory bulb. Multiple in vivo studies have observed blood flow responses in the olfactory bulb evoked by natural olfactory stimulation of odor inhalation and examined the mechanism of neurovascular couplings [19-21]. High-concentration odor inhalation or sustained odorant inhalation can easily produce peripheral adaptation, i.e., a decline in response by olfactory receptor neurons [20]. To improve our neurophysiological understandings of olfactory bulb blood flow response to olfactory input, it is necessary to study the effect of sensory (olfactory) nerve stimulation, in addition to natural olfactory stimulation of odor inhalation. However, no study has examined the 
effect of olfactory nerve stimulation on olfactory bulb blood flow. Therefore, the present study first aimed to clarify whether olfactory nerve stimulation increases blood flow in the olfactory bulb. By varying the stimulus frequencies of olfactory nerve electrical stimulation, we could quantify the strength of odor stimulation. In this study, electrical stimulation of the olfactory nerve using various stimulus parameters on olfactory bulb blood flow was tested. For comparison, blood flow in the frontal cortex and systemic arterial pressure were measured simultaneously.

Our previous study demonstrated that the increased response of olfactory bulb blood flow to odor stimulation is potentiated by the intravenous injection of nicotine $(30 \mu \mathrm{g} / \mathrm{kg})$ [15]. This potentiation effect of nicotine was mediated by the activation of $\alpha 4 \beta 2$-like nicotinic acetylcholine receptors (nAChRs) in the brain [15]. In the present study, we also examined whether the intravenous injection of nicotine potentiated the olfactory bulb blood flow response.

\section{Methods}

\section{Experimental animals}

The experiments were performed on 10 male adult Wistar $(n=5)$ or Fisher $(n=5)$ rats (body weight, 300 $440 \mathrm{~g} ; 4-8$ months old). All data from different strains were combined because there were essentially no differences in their responses. The study was conducted in accordance with the Guidelines for Proper Conduct of Animal Experiments (established by the Science Council of Japan in 2006) and was approved by the animal care and use committee of Tokyo Metropolitan Institute of Gerontology.

\section{General surgery and anesthesia}

The rats were anesthetized with urethane $(1.2-1.4 \mathrm{~g} / \mathrm{kg}$, subcutaneously), after the initial inhalation of $4.2 \%$ sevoflurane for approximately $5 \mathrm{~min}$. Respiration was maintained using an artificial respirator (model 683, Harvard, Massachusetts, USA) through a tracheal cannula. The end-tidal $\mathrm{CO}_{2}$ concentration was maintained at $3.0-4.0 \%$ via monitoring with a respiratory gas monitor (Microcap, Oridion Medical, Jerusalem, Israel). Arterial blood pressure was measured through a catheter inserted into a femoral artery with a pressure transducer (TP-400T, Nihon Kohden, Tokyo, Japan). Body temperature was measured rectally and continuously using a thermistor and maintained at approximately $37.5{ }^{\circ} \mathrm{C}$ using a body temperature control system (ATB-1100, Nihon Kohden). The depth of anesthesia was adjusted with additional urethane doses $(100 \mathrm{mg} / \mathrm{kg}$, i.v. via a catheter inserted into a femoral vein) when necessary and by monitoring body movement, blood pressure stability, and respiratory movement.

\section{Measurement of regional blood flow in the olfactory bulb and cortex}

The animals were mounted on a stereotaxic instrument (SR-5R-HT, Narishige, Tokyo, Japan) in a prone position. Regional cerebral blood flow was measured using laser Doppler flowmetry (in four rats) or laser speckle contrast imaging (in six rats), as described previously $[9,15,22-24]$. We used either laser Doppler flowmetry or laser speckle contrast imaging, depending on the purpose of each experiment. To analyze olfactory blood flow responses at different intensities and frequencies of olfactory nerve stimulation, we used mainly laser Doppler flowmetry because of technical convenience. To analyze spatiotemporal changes in cerebral blood flow following olfactory nerve stimulation, we used laser speckle contrast imaging which provide a wide field of view. To analyze pharmacological effects, we used both devices in four animals each.

For laser Doppler flowmetry, two recording probes (diameter, $0.8 \mathrm{~mm}$ ) of the laser Doppler flowmeter (ALF 21D, Advance, Tokyo, Japan) were placed, avoiding the visible blood vessels, on the dorsal surface of the unilateral olfactory bulb $(\mathrm{AP}=+7.0-8.0 \mathrm{~mm}$ from bregma, $L=0.6-1.6 \mathrm{~mm}$ to the midline), and the frontal cortex (AP $=+1.0-4.0 \mathrm{~mm}, L=1.0-4.0 \mathrm{~mm}$ ) $[25,26]$ following a partial craniotomy. The flowmeter probes were fixed with balancing holders (ALF-B, Advance).

For laser speckle contrast imaging, after craniotomy, the surface of the brain was covered with mineral oil, followed by a glass coverslip. The laser speckle contrast imaging device was then fixed, and the zoom was adjusted to cover the dorsal surface of the brain from the most anterior part of the olfactory bulb to the frontal cortex. Laser speckle contrast imaging was performed using a Moor full-field perfusion imaging device consisting of an infrared laser diode (785 nm wavelength) and a CCD camera (Moor Instruments, Devon, UK). The viewing field covered approximately $108 \mathrm{~mm}^{2}(12 \mathrm{~mm} \times 9 \mathrm{~mm})$ with a matrix of $150 \times 116$ pixels, providing an approximate resolution of $79 \mu \mathrm{m}$ per pixel. The images were sampled at $25 \mathrm{~Hz}$.

To analyze spatial changes in blood flow, the acquired images were further averaged over 1-s time bins. The baseline image just before olfactory nerve stimulation ( -1 to $0 \mathrm{~s}$ ) was then subtracted from the other images to assess the relative blood flow changes. To quantify the temporal blood flow changes (in arbitrary units), time courses were extracted in three regions of interest (ROIs) depicted by $1.0-\mathrm{mm}$-diameter circles positioned bilaterally, avoiding the visible blood vessels, in the area 
of the olfactory bulb ( $\mathrm{AP}=+7.0-8.0 \mathrm{~mm}$ from bregma, $L=0.6-1.6 \mathrm{~mm}$ to the midline), and the frontal cortex $(\mathrm{AP}=+1.0-4.0 \mathrm{~mm}, L=1.0-4.0 \mathrm{~mm})$ ipsilateral to the side of olfactory nerve stimulation.

\section{Stimulation of the olfactory nerve}

The unilateral olfactory nerve was electrically stimulated as described previously [27]. For stimulation, an additional craniotomy was performed over the olfactory nerve just caudal to the cribriform plate [27]. A coaxial metal electrode with an outer diameter of $0.2 \mathrm{~mm}$ was stereotaxically inserted into the olfactory nerve bundle approximately at $4 \mathrm{~mm}$ posterior to the nasofrontal suture and approximately $0.8 \mathrm{~mm}$ lateral to the midline. Electrical stimulation of the olfactory nerve was performed using a stimulator (SEN-3301, Nihon Kohden) and stimulus isolation unit (SS-202J, Nihon Kohden). Repetitive electrical square pulse stimuli of $0.5 \mathrm{~ms}$ in width with varying intensities $(20-400 \mu \mathrm{A})$ and frequencies $(0.5-200 \mathrm{~Hz})$ were applied for $5 \mathrm{~s}$. To examine the relationships between the intensities and frequencies of electrical stimulation of the olfactory nerve and magnitudes of blood flow responses in the olfactory bulb, the stimuli were applied in the order of low to high intensities or frequencies, and the minimum interval between stimuli was $1 \mathrm{~min}$. To examine the effect of nicotine on the olfactory nerve stimulation-induced blood flow response in the olfactory bulb, the parameters of electrical stimulation were set at an intensity of $300 \mu \mathrm{A}$ with three different frequencies $(2,20$, and $100 \mathrm{~Hz})$. The order of these three different frequencies was random, and the minimum interval between stimuli was 3 min.

\section{Drug administration}

(-) Nicotine (Tokyo Kasei Kogyo, Tokyo, Japan) was diluted in saline to final concentration of $30 \mu \mathrm{g} / \mathrm{kg}$ body weight (calculated as the free base). Nicotine was injected slowly (duration of approximately $1 \mathrm{~min}$ ) through a femoral vein. We chose a dose of $30 \mu \mathrm{g} / \mathrm{kg}$ nicotine because our previous report found that this dose was optimal for stimulating nicotinic cholinergic receptors in the brain parenchyma without causing marked changes in systemic arterial pressure [28] and was effective for enhancing olfactory bulb blood flow responses to odor [15].

\section{Data collection and statistical analysis}

The obtained analog signals of regional blood flow and systemic arterial pressure were recorded on a PC using an A/D converter (Micro 1401 mkII, Cambridge Electronic Design, Cambridge, UK) with Spike 2 software (Spike 2, Cambridge Electronic Design) for offline analyses.

All values are presented as the mean \pm SEM. Changes of regional blood flow and mean arterial pressure evoked by olfactory nerve stimulation were assessed by oneway repeated-measures ANOVA followed by Dunnett's multiple comparison test. The comparison of changes in regional blood flow to olfactory nerve stimulation before and after nicotine injection were conducted using two-way repeated-measures ANOVA followed by Bonferroni's multiple comparison test or Wilcoxon's matched-pairs signed-rank test. $p<0.05$ was considered statistically significant.

\section{Results \\ Blood flow response to olfactory nerve stimulation in the olfactory bulb}

The effects of electrical stimulation of the unilateral olfactory nerve with different stimulus intensities (Fig. 1a, b) and frequencies (Fig. 1c-e) on regional blood flow in the olfactory bulb ipsilateral to the stimulation were examined.

When the olfactory nerve was electrically stimulated with various stimulus intensities at a constant frequency of $20 \mathrm{~Hz}$, stimulation at intensities of $\geq 100 \mu \mathrm{A}$ clearly produced a current-dependent increase in the blood flow in the olfactory bulb, as shown in sample recordings in Fig. 1a. The blood flow in the olfactory bulb usually started to increase approximately $1 \mathrm{~s}$ after the onset of stimulation and peaked near the end of the 5-s stimulation. The peak (maximum) responses of olfactory bulb blood flow following stimulation of the olfactory nerve with different intensities in six rats are summarized in Fig. 1b. Olfactory bulb blood flow significantly increased in response to stimulus intensities of $\geq 100 \mu \mathrm{A}$. The responses were largest to intensities of 300 and $400 \mu \mathrm{A}$. With a stimulus intensity of $300 \mu \mathrm{A}$, the blood flow reached its maximum of $30 \pm 7 \%$ (range $17-53 \%$ ). We used a maximal intensity of $300 \mu \mathrm{A}$ for olfactory nerve stimulation in the subsequent experiments.

Figure 1c-e presents sample recordings and summarized graphs ( $n=6$ rats) of olfactory bulb blood flow responses to olfactory nerve stimulation with various stimulus frequencies at a constant intensity of $300 \mu \mathrm{A}$. Olfactory bulb blood flow was significantly increased by stimulation with frequencies of $\geq 5-200 \mathrm{~Hz}$ (Fig. 1c). The response was largest at a frequency of $20 \mathrm{~Hz}$, reaching $26 \pm 6 \%$ (range 11-55\%; Fig. 1d). Stimulation with higher frequencies of $50-200 \mathrm{~Hz}$ produced a second peak blood flow response approximately 14-29 s after the onset of olfactory nerve stimulation (Fig. 1c, e).

\section{Spatiotemporal changes in cerebral blood flow following olfactory nerve stimulation}

Figure $2 b-d$ presents the laser speckle flow images in a rat before and after olfactory nerve stimulation at $300 \mu \mathrm{A}$ and $20 \mathrm{~Hz}$ for $5 \mathrm{~s}$. Electrical stimulation of the olfactory 


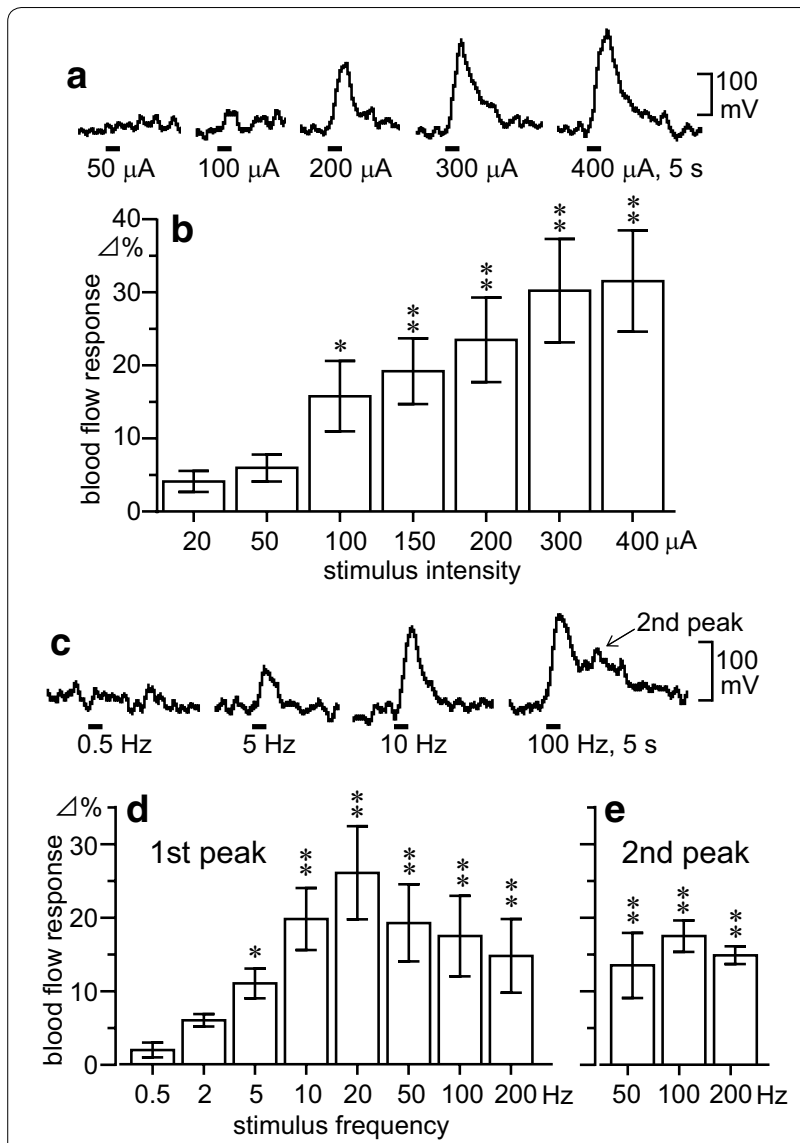

Fig. 1 Olfactory bulb blood flow responses following olfactory nerve stimulation. The effects of various intensities $(\mathbf{a}, \mathbf{b})$ and frequencies (c-e) of electrical stimulation of the unilateral olfactory nerve on regional blood flow in the olfactory bulb ipsilateral to the stimulus. a, b Stimulus frequency, $20 \mathrm{~Hz}$. c-e Stimulus intensity, $300 \mu \mathrm{A}$. a, c Sample recordings of regional blood flow in the olfactory bulb. $\mathbf{b}, \mathbf{d}$, e Summarized responses of regional blood flow in the olfactory bulb measured at the maximal level within $8 \mathrm{~s}$ (1st peak) or later (2nd peak) after the onset of stimulation, and expressed as the percentage increase from the pre-stimulus basal blood flow (mean value of the 10-s duration). Each column and vertical bar represents the mean $\pm \operatorname{SEM}(n=6)$. The data depict blood flow changes measured by laser Doppler $(n=4)$ or laser speckle $(n=2)$ flowmetry. ${ }^{*} p<0.05,{ }^{* *} p<0.01$ : significantly different from the responses at an intensity of $20 \mu \mathrm{A}(\mathbf{b})$ or frequency of $0.5 \mathrm{~Hz}(\mathbf{d})$, using one-way repeated-measures ANOVA followed by Dunnett's multiple comparison test

nerve produced a marked increase in blood flow in the olfactory bulb ipsilateral to the stimulus at 5-6 s after the onset of stimulation. By contrast, the stimulation produced an extremely slight increase in blood flow in the olfactory bulb contralateral to the stimulus. Blood flow in the bilateral frontal cortices was not affected by the stimulation.

Figure 2e summarizes the time courses of the responses of regional blood flow in the ipsilateral and contralateral

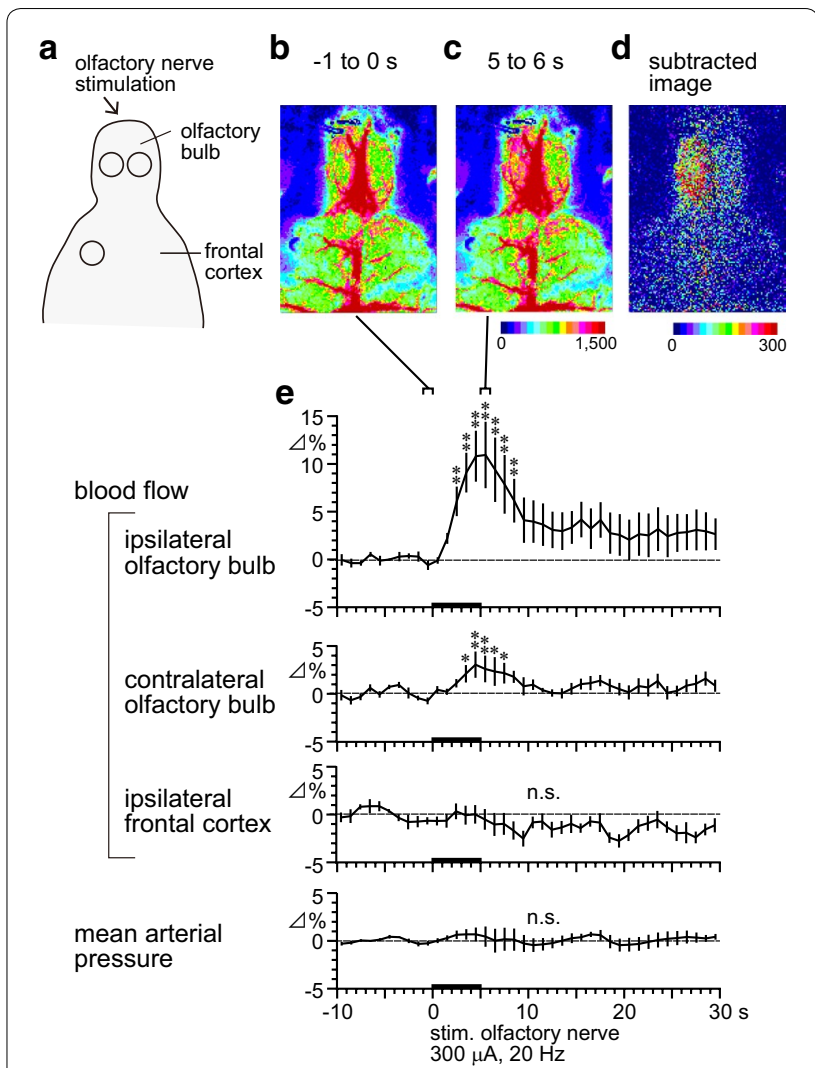

Fig. 2 Spatiotemporal changes in regional cerebral blood flow following olfactory nerve stimulation. a Schema showing the area of blood flow recorded using a laser speckle contrast imager. b-d Sample recording of regional cerebral blood flow in one rat. $\mathbf{b}, \mathbf{c}$ Averaged signal over selected periods of $1 \mathbf{s}$. $\mathbf{d}$ Differential signal changes obtained from $\mathbf{b}$ and $\mathbf{c}$ when subtracting the baseline ( $\mathbf{b}$ -1 to 0 s) signal from the subsequent image (c $5-6$ s). e Percentage signal changes in the ipsilateral and contralateral olfactory bulb and frontal cortex in response to olfactory nerve stimulation (data extracted from the region of interest indicated by the black circle in a) and mean arterial pressure averaged every $1 \mathrm{~s}$. Changes in each parameter are expressed as the percentages of corresponding basal values (mean value for $10 \mathrm{~s}$ before time zero). Each point and vertical bar represent the mean $\pm \operatorname{SEM}(n=6) .{ }^{*} p<0.05,{ }^{* *} p<0.01$ : significantly different from the pre-stimulus basal values ( -1 to $0 \mathrm{~s}$ ) using one-way repeated-measures ANOVA followed by Dunnett's multiple comparison test

olfactory bulb and ipsilateral frontal cortex to olfactory nerve stimulation, and mean arterial pressure measured every $1 \mathrm{~s}$ in six rats. Blood flow in the olfactory bulb ipsilateral to the olfactory nerve stimulation was significantly increased by the stimulation. After the onset of stimulation, a significant increase in blood flow appeared at 2-3 s and peaked near the end of the stimulation period, and after which blood flow gradually returned to the prestimulus basal level after the cessation of stimulation. The maximum change of blood flow in the ipsilateral 
olfactory bulb was $11 \pm 3 \%$ (range $3-26 \%$ ) at 5-6 s. Blood flow in the olfactory bulb contralateral to the olfactory nerve stimulation was slightly increased following the stimulation. The maximum change of blood flow in the contralateral olfactory bulb was $3 \pm 1 \%$ at $4-5 \mathrm{~s}$. Moreover, blood flow in the frontal cortex ipsilateral to the olfactory nerve stimulation and mean arterial pressure exhibited no obvious changes following olfactory nerve stimulation.

From these results, we focused on blood flow in the olfactory bulb ipsilateral to the olfactory nerve stimulation, and the effect of nicotine on the response was examined.

\section{Effect of intravenous nicotine on the olfactory bulb blood flow response induced by olfactory nerve stimulation} We chose three stimulus frequencies $(2,20$, and $100 \mathrm{~Hz})$ at a constant intensity of $300 \mu \mathrm{A}$ to analyze the effect of nicotine on the olfactory bulb blood flow response. Before the nicotine injection, the olfactory bulb blood flow responses elicited by olfactory nerve stimulation using three different frequencies were confirmed to be stable between two trials.

Figure $3 \mathrm{a}-\mathrm{f}$ shows sample recordings of regional blood flow in the olfactory bulb ipsilateral to the olfactory nerve stimulation with three different frequencies, obtained before (Fig. 3a-c) and at 7-13 min after nicotine (30 $\mathrm{\mu g} /$ $\mathrm{kg}$ ) administration (Fig. $3 \mathrm{~d}-\mathrm{f}$ ) in a rat. Figure $3 \mathrm{~g}-\mathrm{i}$ summarizes the time course responses of olfactory bulb blood flow to olfactory nerve stimulation using these three frequencies obtained before and after (tested at 5-20 min) nicotine injection in eight rats. Stimulation with a frequency of $2 \mathrm{~Hz}$ produced no obvious changes in blood flow before the nicotine injection (Fig. 3a and black line in g), but it produced a significant increase in blood flow after the nicotine injection $(p<0.01$, assessed using one-way repeated-measures ANOVA; Fig. 3d and red line in $\mathrm{g}$ ). There was a significant difference in the olfactory bulb blood flow response to $2 \mathrm{~Hz}$ stimulation between these two conditions (before vs. after nicotine injection; $p<0.05$, assessed using two-way repeatedmeasures ANOVA). Comparing the increase in olfactory bulb blood flow responses to $20-\mathrm{Hz}$ stimulation before

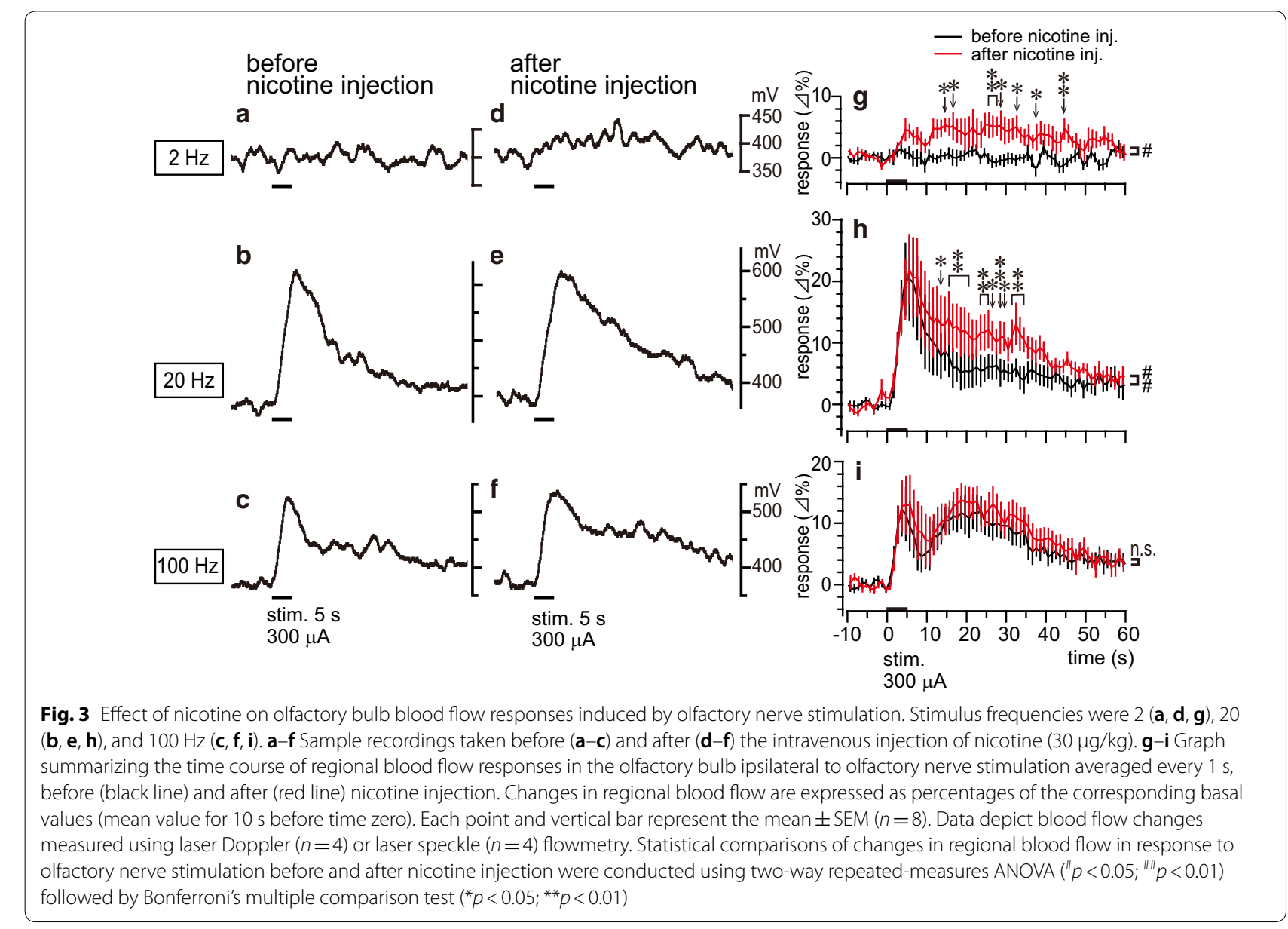


and after nicotine injection, the duration of increased blood flow following olfactory nerve stimulation was prolonged by nicotine administration (Fig. 3b, e, h). There was a significant difference in the olfactory bulb blood flow response to $20-\mathrm{Hz}$ stimulation between these two conditions (before vs. after nicotine injection; $p<0.01$, assessed using two-way repeated-measures ANOVA). The increase in olfactory bulb blood flow evoked by $100-$ $\mathrm{Hz}$ stimulation tended to become larger after the nicotine injection, but there was no statistical difference in blood flow responses between the two conditions (before vs. after nicotine injection; Fig. 3c, f, i). The basal level of blood flow in the olfactory bulb and mean arterial pressure were not changed significantly by nicotine administration $(30 \mu \mathrm{g} / \mathrm{kg})$. In more detail, the averaged values for $10 \mathrm{~s}$ just before stimulation at $20 \mathrm{~Hz}$ were compared before and after nicotine injection. Olfactory bulb blood flow before injection was $100 \%$ vs. $102 \pm 1 \%$ after, and mean arterial pressure before injection $77 \pm 3 \mathrm{mmHg}$ vs. $73 \pm 3 \mathrm{mmHg}$ after.

Using the same data shown in Fig. 3, the peak response (\%), duration of response (s), and 60-s area (\%) for olfactory bulb blood flow response following stimulation of the olfactory nerve using three different frequencies were analyzed and compared between before and after nicotine injection (Fig. 4). Concerning the olfactory bulb blood flow responses to $2-\mathrm{Hz}$ stimulation, nicotine significantly augmented the peak response (Fig. 4a), the duration of response (Fig. 4b), and the area response (Fig. 4c). Concerning the olfactory bulb blood flow responses to $20-\mathrm{Hz}$ stimulation, nicotine did not change the peak response (Fig. 4d), while it significantly prolonged the duration of response (Fig. 4e), thereby significantly augmented the 60-s area response by approximately 1.5 -fold (Fig. 4f). Conversely, olfactory bulb blood flow responses to $100 \mathrm{~Hz}$ stimulation were not significantly changed by nicotine injection in any analyses (Fig. $4 \mathrm{~g}-\mathrm{i}$ ).

The augmented olfactory bulb blood flow responses to 2- and $20-\mathrm{Hz}$ stimulation obtained at 5-20 min after the injection of nicotine had dissipated, when measured at 30-90 min after nicotine injection in four rats tested.

\section{Discussion}

Our previous study reported that activation of $\alpha 4 \beta 2$-like subtype nAChRs in the brain by the intravenous injection of nicotine potentiates the odor stimulation (5\% amyl acetate)-induced increase in olfactory bulb blood flow response in anesthetized rats [15]. In the present study, we first demonstrated that electrical stimulation of the olfactory nerve instead of odor stimulation increased blood flow in the olfactory bulb. Furthermore, we found that $\mathrm{nAChR}$ activation via the intravenous injection of nicotine potentiates those olfactory bulb blood flow responses. This study found that the nicotine-induced potentiation of olfactory bulb blood flow responses occurred when the olfactory nerve was stimulated at frequencies of 2 and $20 \mathrm{~Hz}$, but not $100 \mathrm{~Hz}$. The present findings provide additional evidence that $\mathrm{nAChR}$ activation potentiates olfactory bulb blood flow responses to olfactory input, and the potentiation occurs when the strength of the input is weak and intermediate, but not strong. Our new findings, which used olfactory nerve stimulation instead of natural olfactory stimulation by odor inhalation, provide stronger neurophysiological evidence that potentiation of olfactory input-induced increase in olfactory bulb blood flow by nAChR activation occurs at the level of the olfactory bulb.

In the olfactory system, olfactory sensory neurons (olfactory nerve) in the olfactory epithelium detect odorants and send information about the sense of smell to the olfactory bulb. The olfactory nerve was spontaneously active at approximately $1.2 \mathrm{~Hz}$ in an olfactory nerve recording study conducted in anesthetized rats [17]. The firing rate of the olfactory nerve increased with increasing odor concentration, reaching approximately $86 \mathrm{~Hz}$ in an in vivo olfactory nerve recording study in rats [17], or even a higher frequency of $200-300 \mathrm{~Hz}$ in isolated mouse olfactory sensory neurons [18]. In the present study, before the injection of nicotine, olfactory nerve stimulation (at an intensity of $300 \mu \mathrm{A}$ ) with frequencies of $\geq 5 \mathrm{~Hz}$ produced an increase in blood flow in the olfactory bulb ipsilateral to the nerve stimulation, peaking near the end of the 5-s stimulation. Stimulation of the olfactory nerve at higher frequencies of $50-200 \mathrm{~Hz}$ produced a second peak blood flow response approximately $14-29 \mathrm{~s}$ after the onset of the stimulation.

It is well established that odor stimulation increases regional blood flow in the rodent olfactory bulb, in association with neuronal activities [11-14]. A recent study by Boido et al. [10] revealed a linear relationship between vascular responses in the olfactory bulb to odors and $\mathrm{Ca}^{2+}$ signals from local (principal) neurons, i.e., mitral cells and external tufted cells, in an imaging study in the same mouse and suggested that blood flow in the olfactory bulb can be used as a quantitative marker of synaptic activation. In the present study, the observed increase in olfactory blood flow in response to olfactory nerve stimulation may reflect synaptic activation in the olfactory bulb. In olfactory bulb principal neurons, external tufted cells exhibit a lower threshold (higher sensitivity) for excitation compared with mitral cells in response to olfactory sensory inputs [29-31]. In response to high-frequency $(50 \mathrm{~Hz})$ olfactory nerve stimulation, mitral cells produce sustained responses, whereas external tufted cells respond transiently [32]. We therefore speculated that the first peak olfactory 


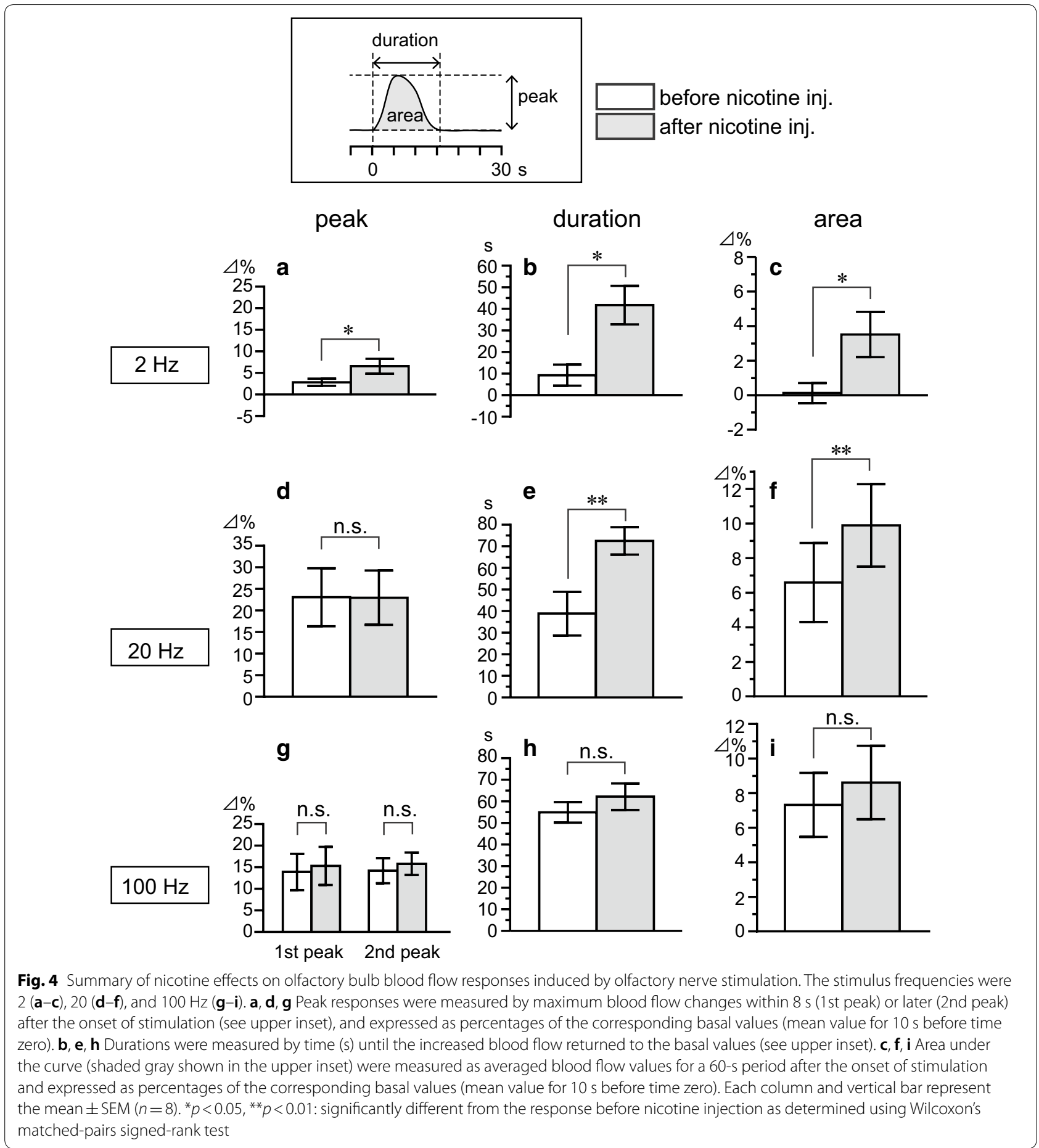

bulb blood flow response evoked by olfactory nerve stimulation may reflect external tufted cell excitation, whereas the second peak olfactory bulb blood flow response evoked by high-frequency olfactory nerve stimulation may largely reflect mitral cell excitation.
In the present study, the magnitude of the first peak blood flow response was largest at $20 \mathrm{~Hz}$ of stimulation and became smaller at higher frequencies $(50-200 \mathrm{~Hz}$ ). Mechanism of this attenuation by high-frequency stimulation is not clear. The olfactory nerve consists of 
unmyelinated axons $[33,34]$ with a variety of diameters (50-400 nm) [33]. High-frequency stimulation may release other vasoactive transmitters [35] in addition to glutamate from different types of olfactory nerve fibers.

The ethmoidal nerve, a branch of the ophthalmic division of the trigeminal nerve, innervates both the olfactory epithelium and the olfactory bulb $[36,37]$ and detects odors-strong irritating odors in particular [38]. In the present study, it is possible that electrical stimulation applied to the olfactory nerve also stimulated nearby ethmoidal nerve. However, electrical stimulation of a sub-branch of the trigeminal nerve (the nasociliary nerve, which contains ethmoidal nerve) reportedly increased regional cortical blood flow in anesthetized rats [39]. In our study, olfactory nerve stimulation produced an increase in olfactory bulb blood flow, but did not change frontal cortical blood flow. We therefore speculated that the ethmoidal nerve is less likely to be stimulated by olfactory nerve stimulation procedure.

The present study demonstrated that the intravenous injection of nicotine $(30 \mu \mathrm{g} / \mathrm{kg})$ potentiated olfactory bulb blood flow responses to olfactory nerve stimulation at frequencies of 2 and $20 \mathrm{~Hz}$, but not $100 \mathrm{~Hz}$. These results suggest that the nicotine-induced potentiation of olfactory bulb responses occurs when the strength of the olfactory input is weak and intermediate, but not strong. In a $\mathrm{Ca}^{2+}$ imaging study using the mouse olfactory bulb, Bendahmane et al. [40] indicated that electrical stimulation of the horizontal limb of the diagonal band of Broca (HDB), which sends cholinergic fibers to the olfactory bulb [41-43], leads to the activity-dependent modulation of glomerular odor responses, whereby weak-to-moderate responses are enhanced and strong responses are reduced. Our present results of nicotine-induced potentiation of olfactory bulb blood flow responses to olfactory nerve stimulation with 2 and $20 \mathrm{~Hz}$, but not with $100 \mathrm{~Hz}$, more or less agree with the results of Bendahmane et al. [40].

Concerning the statistical result of no significant effect of nicotine on olfactory bulb blood flow response to $100 \mathrm{~Hz}$ stimulation (e.g., Fig. $4 \mathrm{i}, n=8, p=0.38$, effect size $=0.38$ ), a type II error (false negatives) is a possibility due to the small number of animals. Several studies have reported that a physiologically appropriate firing rate of olfactory nerve in response to odor is less than approximately $50 \mathrm{~Hz}[32,44,45]$. Therefore, in this study we did not increase the number of animals subjected to $100 \mathrm{~Hz}$ of stimulation for ethical reasons. When designing the protocol of the present experiment, the estimated sample size was based on our previous study of the effect nicotine injection $(30 \mu \mathrm{g} / \mathrm{kg})$ on odor-induced olfactory bulb blood flow response, which increased by $5.9 \pm 3.9 \%$ (mean \pm standard deviation) [15]. With 90\% power and a two-sided significance level of 5\%, the required sample size was 8 , as determined by software calculations $\left(G^{*}\right.$ Power 3.1 [46]). Our decision to test 8 rats was therefore appropriate.

Cholinergic neurons in the basal forebrain including the HDB, as well as the olfactory bulb express the mRNA of multiple subtypes of nAChRs, including the alpha 4 and beta 2 subunits [47-49]. Therefore, we can expect that the nicotine-induced potentiation of olfactory bulb blood flow responses may occur through the activation of nAChRs in cholinergic neurons in the HDB and/or olfactory bulb. Further study is needed to explore the location of nAChRs contributing to the potentiation of olfactory bulb blood flow responses.

Our previous study reported that HDB stimulation increased ACh release, but did not change blood flow in the olfactory bulb [9]. Without odor input, olfactory bulb neurons (principal neurons, i.e., mitral cells and external tufted cells) were not influenced by HDB cholinergic activation as measured by $\mathrm{Ca}^{2+}$ signals [40]. This may explain our previous finding that HDB cholinergic activation did not change blood flow in the olfactory bulb [9]. Our present study found that nAChRs activation potentiates olfactory bulb blood flow in response to olfactory nerve stimulation. We speculated that cholinergic inputs to the olfactory bulb do not directly influence neuronal activity at rest, but potentiate synaptic transmission evoked by olfactory inputs [40], and thereby increase the olfactory bulb blood flow response.

Olfactory function is known to decline in the early stage of Alzheimer's disease [50, 51]. In patients with Alzheimer's disease, atrophy of the basal forebrain cholinergic system [52, 53], as well as reduced $\alpha 4 \beta 2-n A C h R$ availability, especially within the basal forebrain, frontotemporal cortices, and hippocampus [54] has been reported even in the early stage of the disease. Therefore, we can speculate that the functional decline of nicotinic cholinergic transmission as well as the degeneration of basal forebrain cholinergic neurons may be a causative factor for the decline of olfactory function in the early stage of Alzheimer's disease.

Concerning the physiological roles, the nicotineinduced potentiation of increase in olfactory bulb blood flow in response to olfactory input may contribute to the neuronal turnover in the olfactory bulb and short-term olfactory memory [55-57], thereby maintaining olfactory function and cognitive function.

\section{Conclusion}

In conclusion, our present study demonstrated that direct electrical stimulation of the olfactory nerve instead of odor stimulation induced an increase in olfactory bulb blood flow. Furthermore, this study 
found that the activation of nAChRs by intravenous nicotine potentiates the olfactory bulb blood flow response to olfactory input of weak and intermediate intensity. These results prove important evidences of olfactory bulb blood flow response by olfactory nerve stimulation, and of its potentiation through activation of nicotinic cholinergic transmission.

\section{Abbreviation}

nAChR: Nicotinic acetylcholine receptor.

\section{Acknowledgements}

Not applicable.

\section{Authors' contributions}

SU conceived and designed the research and drafted the manuscript. Both authors performed experiments, analyzed data, interpreted the results of experiments, and edited and revised the manuscript. Both authors read and approved the final manuscript.

\section{Funding}

This work was supported by The Japan Health Foundation and the Smoking Research Foundation.

\section{Availability of data and materials \\ The data that support the findings of this study are available from the cor- responding author on reasonable request.}

\section{Ethics approval and consent to participate}

All rat experiments were approved by the Animal Care and Use Committee of Tokyo Metropolitan Institute of Gerontology.

\section{Consent for publication}

Not applicable.

\section{Competing interests}

The authors declare that they have no conflicts of interest.

Received: 7 April 2020 Accepted: 1 June 2020

Published online: 10 June 2020

\section{References}

1. Ballinger EC, Ananth M, Talmage DA, Role LW (2016) Basal forebrain cholinergic circuits and signaling in cognition and cognitive decline. Neuron 91:1199-1218

2. D'Souza RD, Vijayaraghavan S (2014) Paying attention to smell: cholinergic signaling in the olfactory bulb. Front Synaptic Neurosci. https:// doi.org/10.3389/fnsyn.2014.00021

3. Micheau J, Marighetto A (2011) Acetylcholine and memory: a long, complex and chaotic but still living relationship. Behav Brain Res 221:424-429

4. Biesold D, Inanami O, Sato A, Sato Y (1989) Stimulation of the nucleus basalis of Meynert increases cerebral cortical blood flow in rats. Neurosci Lett 98:39-44

5. Sato A, Sato Y (1992) Regulation of regional cerebral blood flow by cholinergic fibers originating in the basal forebrain. Neurosci Res 14:242-274

6. Uchida S, Suzuki A, Kagitani F, Hotta H (2000) Effects of age on cholinergic vasodilation of cortical cerebral blood vessels in rats. Neurosci Lett 294:109-112

7. Uchida S, Hotta H, Misawa H, Kawashima K (2011) Sustained subcutaneous infusion of nicotine enhances cholinergic vasodilation in the cerebral cortex induced by stimulation of the nucleus basalis of Meynert in rats. Eur J Pharmacol 654:235-240
8. Cao WH, Inanami O, Sato A, Sato Y (1989) Stimulation of the septal complex increases local cerebral blood flow in the hippocampus in anesthetized rats. Neurosci Lett 107:135-140

9. Uchida S, Kagitani F (2018) Effect of basal forebrain stimulation on extracellular acetylcholine release and blood flow in the olfactory bulb. J Physiol Sci 68:415-423

10. Boido D, Rungta RL, Osmanski BE, Roche M, Tsurugizawa T, Le Bihan D, Ciobanu L, Charpak S (2019) Mesoscopic and microscopic imaging of sensory responses in the same animal. Nat Commun 10(1):1110. https:// doi.org/10.1038/s41467-019-09082-4

11. Chaigneau E, Tiret P, Lecoq J, Ducros M, Knöpfel T, Charpak S (2007) The relationship between blood flow and neuronal activity in the rodent olfactory bulb. J Neurosci 27:6452-6460

12. Iadecola C (2017) The neurovascular unit coming of age: a journey through neurovascular coupling in health and disease. Neuron 96:17-42

13. Poplawsky AJ, Fukuda M, Murphy M, Kim SG (2015) Layer-specific fMRI responses to excitatory and inhibitory neuronal activities in the olfactory bulb. J Neurosci 35:15263-15275

14. Yang X, Renken R, Hyder F, Siddeek M, Greer CA, Shepherd GM, Shulman RG (1998) Dynamic mapping at the laminar level of odor-elicited responses in rat olfactory bulb by functional MRI. Proc Natl Acad Sci USA 95:7715-7720

15. Uchida S, Ito Y, Kagitani F (2019) Effects of nicotine on odor-induced increases in regional blood flow in the olfactory bulb in rats. J Physiol Sci 69:425-431

16. Connelly T, Savigner A, Ma M (2013) Spontaneous and sensory-evoked activity in mouse olfactory sensory neurons with defined odorant receptors. J Neurophysiol 110(1):55-62. https://doi.org/10.1152/jn.00910.2012

17. Duchamp-Viret P, Chaput MA, Duchamp A (1999) Odor response properties of rat olfactory receptor neurons. Science 284(5423):2171-2174

18. Reisert J, Matthews HR (2001) Response properties of isolated mouse olfactory receptor cells. J Physiol 530(Pt 1):113-122

19. Jukovskaya N, Tiret P, Lecoq J, Charpak S (2011) What does local functional hyperemia tell about local neuronal activation? J Neurosci 31:1579-1582

20. Lecoq J, Tiret P, Charpak S (2009) Peripheral adaptation codes for high odor concentration in glomeruli. J Neurosci 29:3067-3072

21. Petzold GC, Albeanu DF, Sato TF, Murthy VN (2008) Coupling of neural activity to blood flow in olfactory glomeruli is mediated by astrocytic pathways. Neuron 58:897-910

22. Hotta H, Uchida S, Kagitani F, Maruyama N (2011) Control of cerebral cortical blood flow by stimulation of basal forebrain cholinergic areas in mice. J Physiol Sci 61(3):201-209. https://doi.org/10.1007/s1257 6-011-0139-x

23. Piché M, Uchida S, Hara S, Aikawa Y, Hotta H (2010) Modulation of somatosensory-evoked cortical blood flow changes by GABAergic inhibition of the nucleus basalis of Meynert in urethane-anaesthetized rats. J Physiol 588(Pt 12):2163-2171. https://doi.org/10.1113/jphysiol.2010.187633

24. Shiba K, Machida T, Uchida S, Hotta H (2006) Effects of nicotine on regional blood flow in the olfactory bulb in rats. Eur J Pharmacol 546:148-151

25. Paxinos $G$, Watson C (2009) The rat brain in stereotaxic coordinates: compact, 6th edn. Academic Press, Amsterdam

26. Zilles K (1985) The cortex of the rat. Springer, Berlin

27. Elaagouby A, Ravel N, Gervais R (1991) Cholinergic modulation of excitability in the rat olfactory bulb: effect of local application of cholinergic agents on evoked field potentials. Neuroscience 45(3):653-662

28. Uchida S, Kagitani F, Nakayama H, Sato A (1997) Effect of stimulation of nicotinic cholinergic receptors on cortical cerebral blood flow and changes in the effect during aging in anesthetized rats. Neurosci Lett 228:203-206

29. Ezeh PI, Wellis DP, Scott JW (1993) Organization of inhibition in the rat olfactory bulb external plexiform layer. J Neurophysiol 70:263-274

30. Igarashi KM, leki N, An M, Yamaguchi Y, Nagayama S, Kobayakawa K, Kobayakawa R, Tanifuji M, Sakano H, Chen WR, Mori K (2012) Parallel mitral and tufted cell pathways route distinct odor information to different targets in the olfactory cortex. J Neurosci 32:7970-7985

31. Kikuta S, Fletcher ML, Homma R, Yamasoba T, Nagayama S (2013) Odorant response properties of individual neurons in an olfactory glomerular module. Neuron 77:1122-1135

32. Vaaga CE, Westbrook GL (2017) Distinct temporal filters in mitral cells and external tufted cells of the olfactory bulb. J Physiol 595:6349-6362 
33. Blinder KJ, Pumplin DW, Paul DL, Keller A (2003) Intercellular interactions in the mammalian olfactory nerve. J Comp Neurol 466:230-239

34. de Lorenzo AJ (1957) Electron microscopic observations of the olfactory mucosa and olfactory nerve. J Biophys Biochem Cytol 3:839-850

35. Thyssen A, Hirnet D, Wolburg H, Schmalzing G, Deitmer JW, Lohr C (2010) Ectopic vesicular neurotransmitter release along sensory axons mediates neurovascular coupling via glial calcium signaling. Proc Natl Acad Sci USA 107:15258-15263

36. Genovese F, Bauersachs HG, Gräßer I, Kupke J, Magin L, Daiber P, Nakajima J, Möhrlen F, Messlinger K, Frings S (2017) Possible role of calcitonin generelated peptide in trigeminal modulation of glomerular microcircuits of the rodent olfactory bulb. Eur J Neurosci 45:587-600

37. Schaefer ML, Böttger B, Silver WL, Finger TE (2002) Trigeminal collaterals in the nasal epithelium and olfactory bulb: a potential route for direct modulation of olfactory information by trigeminal stimuli. J Comp Neuro 444:221-226

38. Brand G (2006) Olfactory/trigeminal interactions in nasal chemoreception. Neurosci Biobehav Rev 30:908-917

39. Suzuki N, Hardebo JE, Kåhrström J, Owman C (1990) Effect on cortical blood flow of electrical stimulation of trigeminal cerebrovascular nerve fibres in the rat. Acta Physiol Scand 138:307-316

40. Bendahmane M, Ogg MC, Ennis M, Fletcher ML (2016) Increased olfactory bulb acetylcholine bi-directionally modulates glomerular odor sensitivity. Sci Rep 6:25808. https://doi.org/10.1038/srep25808

41. Hamamoto M, Kiyokage E, Sohn J, Hioki H, Harada T, Toida K (2017) Structural basis for cholinergic regulation of neural circuits in the mouse olfactory bulb. J Comp Neurol 525(3):574-591. https://doi.org/10.1002/ cne.24088

42. Rye DB, Wainer BH, Mesulam MM, Mufson EJ, Saper CB (1984) Cortical projections arising from the basal forebrain: a study of cholinergic and noncholinergic components employing combined retrograde tracing and immunohistochemical localization of choline acetyltransferase. Neuroscience 13:627-643

43. Záborszky L, Carlsen J, Brashear HR, Heimer L (1986) Cholinergic and GABAergic afferents to the olfactory bulb in the rat with special emphasis on the projection neurons in the nucleus of the horizontal limb of the diagonal band. J Comp Neurol 243:488-509

44. Ma M, Chen WR, Shepherd GM (1999) Electrophysiological characterization of rat and mouse olfactory receptor neurons from an intact epithelial preparation. J Neurosci Methods 92:31-40

45. Tan J, Savigner A, Ma M, Luo M (2010) Odor information processing by the olfactory bulb analyzed in gene-targeted mice. Neuron 65:912-926

46. Faul F, Erdfelder E, Lang AG, Buchner A (2007) G*Power 3: a flexible statistical power analysis program for the social, behavioral, and biomedical sciences. Behav Res Methods 39:175-191

47. Azam L, Winzer-Serhan U, Leslie FM (2003) Co-expression of alpha7 and beta2 nicotinic acetylcholine receptor subunit mRNAs within rat brain cholinergic neurons. Neuroscience 119:965-977
48. Keiger CJ, Walker JC (2000) Individual variation in the expression profiles of nicotinic receptors in the olfactory bulb and trigeminal ganglion and identification of alpha2, alpha6, alpha9, and beta3 transcripts. Biochem Pharmacol 59:233-240

49. Wada E, Wada K, Boulter J, Deneris E, Heinemann S, Patrick J, Swanson LW (1989) Distribution of alpha 2, alpha 3, alpha 4, and beta 2 neuronal nicotinic receptor subunit mRNAs in the central nervous system: a hybridization histochemical study in the rat. J Comp Neurol 284:314-335

50. Devanand DP, Liu X, Tabert MH, Pradhaban G, Cuasay K, Bell K, de Leon MJ, Doty RL, Stern Y, Pelton GH (2008) Combining early markers strongly predicts conversion from mild cognitive impairment to Alzheimer's disease. Biol Psychiatry 64:871-879

51. Murphy C (2019) Olfactory and other sensory impairments in Alzheimer disease. Nat Rev Neurol 15(1):11-24. https://doi.org/10.1038/s4158 2-018-0097-5

52. Grothe $M$, Heinsen $H$, Teipel S (2013) Longitudinal measures of cholinergic forebrain atrophy in the transition from healthy aging to Alzheimer's disease. Neurobiol Aging 34:1210-1220

53. Whitehouse PJ, Price DL, Struble RG, Clark AW, Coyle JT, DeLong MR (1982) Alzheimer's disease and senile dementia: loss of neurons in the basal forebrain. Science 215:1237-1239

54. Sabri O, Meyer PM, Gräf $S$, Hesse S, Wilke S, Becker GA, Rullmann M, Patt M, Luthardt J, Wagenknecht G, Hoepping A, Smits R, Franke A, Sattler B, Tiepolt S, Fischer S, Deuther-Conrad W, Hegerl U, Barthel H, Schönknecht P, Brust P (2018) Cognitive correlates of a4 $\beta 2$ nicotinic acetylcholine receptors in mild Alzheimer's dementia. Brain 141:1840-1854

55. Gengatharan A, Bammann RR, Saghatelyan A (2016) The role of astrocytes in the generation, migration, and integration of new neurons in the adult olfactory bulb. Front Neurosci 10:149. https://doi.org/10.3389/fnins 2016.00149

56. Mechawar N, Saghatelyan A, Grailhe R, Scoriels L, Gheusi G, Gabellec MM, Lledo PM, Changeux JP (2004) Nicotinic receptors regulate the survival of newborn neurons in the adult olfactory bulb. Proc Natl Acad Sci USA 101:9822-9826

57. Ogino T, Sawada M, Inada H, Nabekura J, Sawamoto K (2017) The role of blood flow in neuronal turnover in the adult olfactory bulbs. In: JNS meeting planner, Makuhari, Japan. Program No 2P-012 Neuroscience Society 2017 Online

\section{Publisher's Note}

Springer Nature remains neutral with regard to jurisdictional claims in published maps and institutional affiliations.
Ready to submit your research? Choose BMC and benefit from:

- fast, convenient online submission

- thorough peer review by experienced researchers in your field

- rapid publication on acceptance

- support for research data, including large and complex data types

- gold Open Access which fosters wider collaboration and increased citations

- maximum visibility for your research: over $100 \mathrm{M}$ website views per year

At BMC, research is always in progress.

Learn more biomedcentral.com/submissions 